\title{
THE ELECTRODISSOLUTION OF BASE PALLADIUM IN RELATION TO THE OXYGEN ELECTROADSORPTION AND ELECTRODESORPTION IN SULPHURIC ACID SOLUTION
}

\author{
A.E. BOLZÁN, M.E. MARTINS and A.J. ARVIA \\ Instituto de Investigaciones Fisicoquimicas Téoricas y Aplicadas, INIFTA, Casilla de Correo 16, Sucursal 4, \\ 1900 La Plata (Argentina)
}

(Received 5th December 1983; in revised form 27th February 1984)

\begin{abstract}
The electrodissolution of palladium electrode immersed in $1 M \mathrm{H}_{2} \mathrm{SO}_{4}$ under both repetitive triangular potential sweeps and combined potential perturbation functions has been investigated by using the rotating ring-disc electrode technique. The contribution of palladium electrodissolution in the voltammogram changes in going from the first potential scan to the following ones. This contribution also depends on the characteristics of the potential perturbation programme applied to the electrode. Different potential ranges associated with the formation of soluble palladium(II) are distinguished, which correlate with those corresponding to electrochemical reactions already established. The results are explained through a competititve reaction pathway involving the formation of $\operatorname{Pd}(\mathrm{OH})$ and $\mathrm{Pd}(\mathrm{OH})^{+}$intermediate species. The influence of ageing effects and anion adsorption on the formation of soluble palladium(II) is also discussed.
\end{abstract}

\section{INTRODUCTION}

In acidic solutions palladium metal electrodissolves yielding the $\mathrm{Pd}\left(\mathrm{H}_{2} \mathrm{O}\right)_{4}^{2+}$ ion at potentials lower than $1.0 \mathrm{~V}$ (vs. SHE), although at higher potentials an oxide layer is electroformed which passivates the electrode [1-9]. Under comparable conditions the electrodissolution rate of palladium in $1 M$ sulphuric acid under cyclic triangular perturbation is greater than that of platinum [5]. Palladium electrodissolution is obviously enhanced in the presence of complexing agents in solution, including halide ions [10-12]. However, the extent to which palladium electrodissolution contributes to the overall oxide electroformation depends both on the history of the electrode and on the characteristics of the electrical perturbation programme applied to the electrode [13]. Previously reported data on palladium electrodes in acid using the rotating ring-disc electrode technique show that the production of soluble $\mathrm{Pd}^{2+}$ during a triangular potential cycling takes place both during the positive and negative potential scans $[6,14]$. Consequently, in this case, the electrodissolution of palladium should be considered when dealing with electrochemical reactions such as oxygen sorption processes and, in general, those reactions occurring at positive potentials $[15,16]$. 
The present paper refers to the yield of soluble aqueous $\mathrm{Pd}^{2+}$ species during the anodization of polycrystalline palladium in $1 \mathrm{M}$ sulphuric acid when either cyclic triangular potential sweeps or combined potential perturbation programmes are applied to the electrode, using in both cases the rotating ring-disc technique, Changes in the voltammogram in going from the first potential sweep to the following ones are reported and interpreted according to a likely reaction pathway.

\section{FXPERIMENTAI.}

The palladium ring-disc electrode was prepared by electrodepositing palladium on a platinum ring-disc electrode (Taccusel type EAD 10.000, disc geometric area $0.126 \mathrm{~cm}^{2}$, collection efficiency $0.25 \pm 0.05$ ) [17]. Before palladium electroplating, the electrode was polished with alumina $(0.3$ and $0.05 \mu \mathrm{m})$ and later immersed for $5 \mathrm{~min}$ in a $1: 1 \mathrm{HNO}_{3}+\mathrm{H}_{2} \mathrm{SO}_{4}$ mixture. The electrodeposition of palladium on both the disc and the ring was made from a $2 \% \mathrm{PdCl}_{2}$ solution in $0.1 \mathrm{M} \mathrm{HCl}$ at $0.4 \mathrm{~V}$ (vs. $\mathrm{SHE}$ ). For the disc, a macroscopically uniform and reproducible palladium electrodeposit was obtained after $60 \mathrm{~s}$ electrolysis under rotation at $2000 \mathrm{rpm}$, while for the ring electrolysis was carried out with quiescent solution rotation for $30 \mathrm{~s}$. After palladium electrodeposition, the electrode was repeatedly rinsed in triply-distilled water and left in $1 \mathrm{M} \mathrm{H}_{2} \mathrm{SO}_{4}$ for $30 \mathrm{~min}$ at open circuit, at $2000 \mathrm{rpm}$ to facilitate the removal of traces of chloride ion sorbed on the electrodeposited metal. Finally, the electrode was rinsed in fresh $1 \mathrm{M} \mathrm{H}_{2} \mathrm{SO}_{4}$, placed into the electrolysis cell (Tacussel cell type XLRC10) containing $1 \mathrm{M} \mathrm{H}_{2} \mathrm{SO}_{4}$, and subjected to a repetitive triangular potential scan (RTPS) at $0.2 \mathrm{~V} / \mathrm{s}$ from $E_{\mathrm{s}, \mathrm{c}}$ to $E_{\mathrm{s}, \mathrm{a}}$ for ca. $180 \mathrm{~min}$ to attain a stable potential/current $\left(E_{\mathrm{D}} / I_{\mathrm{D}}\right)$ profile $\left(E_{\mathrm{s}, \mathrm{c}}=0.35 \mathrm{~V}\right.$, and $\left.0.87 \mathrm{~V} \leqslant E_{\mathrm{s}, \mathrm{a}} \geqslant 1.52 \mathrm{~V}\right)$. The rotation speed $(\omega)$, which was controlled with an Asservitex 10000 Tacussel device, was varied in the range $500 \leqslant \omega \leqslant 8000 \mathrm{rpm}$. A platinum counter-electrode and a $\mathrm{Hg} / \mathrm{Hg}_{2} \mathrm{SO}_{4} / 0.5 \mathrm{M} \mathrm{H}_{2} \mathrm{SO}_{4}$ reference electrode $\left(E^{\circ}(\mathrm{SHE})=0.679 \mathrm{~V}\right)$ were used. Potentials in the text are referred to the RHE scale. The potential difference between the SHE and RHE is $0.002 \mathrm{~V}$. The current at the ring was corrected for current leakage through the insulating ring, which was of the order of $10^{6}-10^{7} \Omega$.

The electrolyte $\left(1 \mathrm{M} \mathrm{H}_{2} \mathrm{SO}_{4}\right)$ was prepared from $98 \% \mathrm{H}_{2} \mathrm{SO}_{4}$ (Merck p.a.) and triply-distilled water, which satisfied the purity test reported in the literature [18]. The electrolyte was deaerated by continuous bubbling of purified nitrogen through the system. A double potentiostat, which was developed on the basis of that described in ref. 19, coupled to a multiple function generator (LYP GRM3) and a Hewlett-Packard 7046 B X-Y recorder was used. Runs were made at room temperature.

\section{RESULTS}

The potentiodynamic $E_{\mathrm{D}} / I_{\mathrm{D}}$ profile initiated from $E_{\mathrm{s}, \mathrm{c}}=0.35 \mathrm{~V}$ up to $E_{\mathrm{s}, \mathrm{a}}=1.52$ $\mathrm{V}$ at $2000 \mathrm{rpm}$ and $0.2 \mathrm{~V} / \mathrm{s}$ and continued from $E_{\mathrm{s} . \mathrm{a}}=1.52 \mathrm{~V}$ to $E_{\mathrm{s} . \mathrm{c}}=0.345 \mathrm{~V}$ (Fig. 1) shows considerable changes, particularly in the positive-going potential scan, 
during the potential cycling. The O-electroadsorption in the stabilized profile [13] $(0.78-1.52 \mathrm{~V}$ range) is appreciably inhibited in the initial potential sweep, but, in contrast, a large anodic current is recorded in the 1.08-1.28 V range. The charge of the O-electroreduction profile during the potential cycling increases slightly, although under rotation no current associated with palladium electrodeposition is observed, as was the case for static palladium electrodes [13]. The ring current $\left(I_{\mathrm{R}}\right)$ at $E_{\mathrm{R}}=0.38 \mathrm{~V}$ vs. disc potential $\left(E_{\mathrm{D}}\right)$ profile shows regions of a constant cathodic current and cathodic current peaks at well-defined potential ranges (Fig. 1).

The response $\left(I_{\mathrm{R}}\right)$ of the ring-electrode held at $E_{\mathrm{R}}=0.38 \mathrm{~V}$, i.e. at a potential more negative than that of palladium electrodeposition, exhibits a net cathodic current which is related to the anodic current in the disc recorded in the $1.0-1.52 \mathrm{~V}$ range during the first positive potential scan. During the reverse scan, there is a limiting cathodic current in the ring while the potential in the disc covers a range

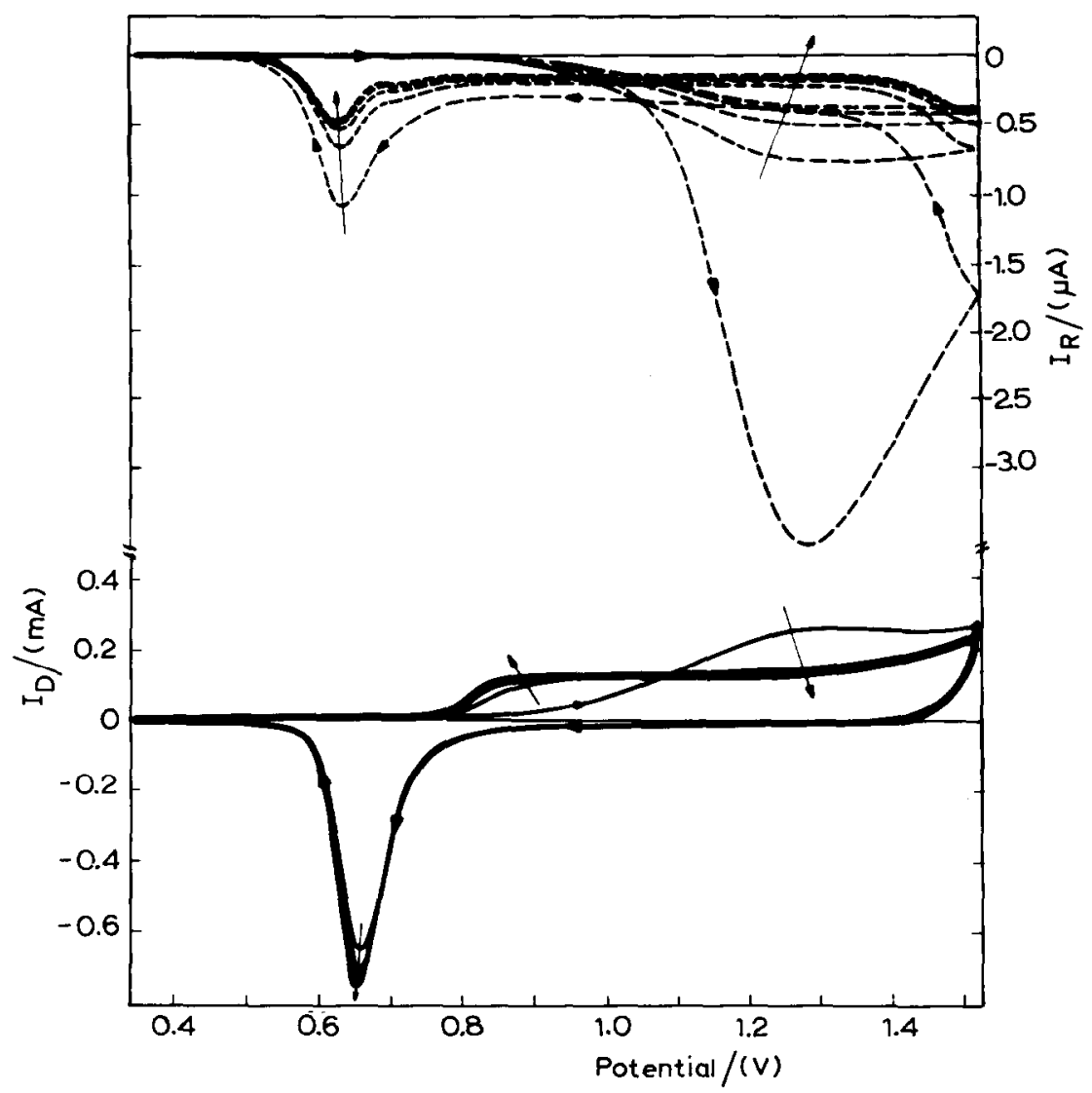

Fig. 1. RTPS $E_{\mathrm{D}} / I_{\mathrm{D}}$ and $E_{\mathrm{D}} / I_{\mathrm{R}}$ profiles at $0.2 \mathrm{~V} / \mathrm{s}$. $E_{\mathrm{R}}=0.38 \mathrm{~V} ; \mathrm{Pd} / 1 M \mathrm{H}_{2} \mathrm{SO}_{4} ; \omega=2000 \mathrm{rpm}$. The first to fifth repetitive profiles are shown. 
from 1.38 to $0.83 \mathrm{~V}$, and finally, when the potential range of the O-electroreduction peak is attained in the disc, two cathodic current contributions are observed at the ring, the main one at $E_{\mathrm{D}}=0.63 \mathrm{~V}$, just in the middle of the current descending branch of the $\mathrm{O}$-electroreduction peak. Another contribution appears as a shoulder at a potential which coincides with that of the ascending branch of the O-electroreduction peak at the disc. These cathodic current contributions at the ring decrease during potential cycling to attain a limiting value when the stabilized $E_{\mathrm{D}} / I_{\mathrm{D}}$ profile is reached. It should be noted that only when the stabilized $E_{\mathrm{D}} / I_{\mathrm{D}}$ profile has been reached does the ring current at $E_{\mathrm{R}}$ vs. disc potential profile approach the shape of those reported earlier in the literature [6]. The same results are obtained when $E_{\mathrm{R}}$ is lower than $0.64 \mathrm{~V}$, the potential at which electrodissolution of palladium at the ring takes place. These runs conclusively show that soluble $\mathrm{Pd}^{2+}$ is produced during both the positive and negative potential scans from palladium in $1 \mathrm{M} \mathrm{H}_{2} \mathrm{SO}_{4}$ as it occurs at lower concentration in the same electrolyte [6].

When $E_{\mathrm{s} . \mathrm{a}}$ is gradually increased or decreased during the RTPS (Fig. 2), the cathodic ring current always appears when the O-electroadsorption threshold potential is reached. There is also a clear correspondence between the O-electrodesorption peak at the disc and the cathodic current peak at the ring electrode. The influence of either increasing or decreasing $E_{\mathrm{s}, \mathrm{a}}$, on the $E_{\mathrm{D}} / I_{\mathrm{D}}$ profiles, already pointed out in a previous publication [13], is also reflected in the corresponding response of the ring electrode $\left(I_{\mathrm{R}}\right)$. In both cases, there is a potential, $E_{\mathrm{i}}=0.98 \mathrm{~V}$ (ca. $1.0 \mathrm{~V}$ ), at which the current ratio at the ring during the positive- $\left(I_{\mathrm{R}}^{+}\right)$and the negative- $\left(I_{\mathrm{R}}^{-}\right)$going potential scans is equal to one. Above $E_{\mathrm{i}}, I_{\mathrm{R}}^{+} / I_{\mathrm{R}}^{-}$is greater than one, apparently approaching a ratio equal to two, while the opposite occurs below $E_{1}$. These runs

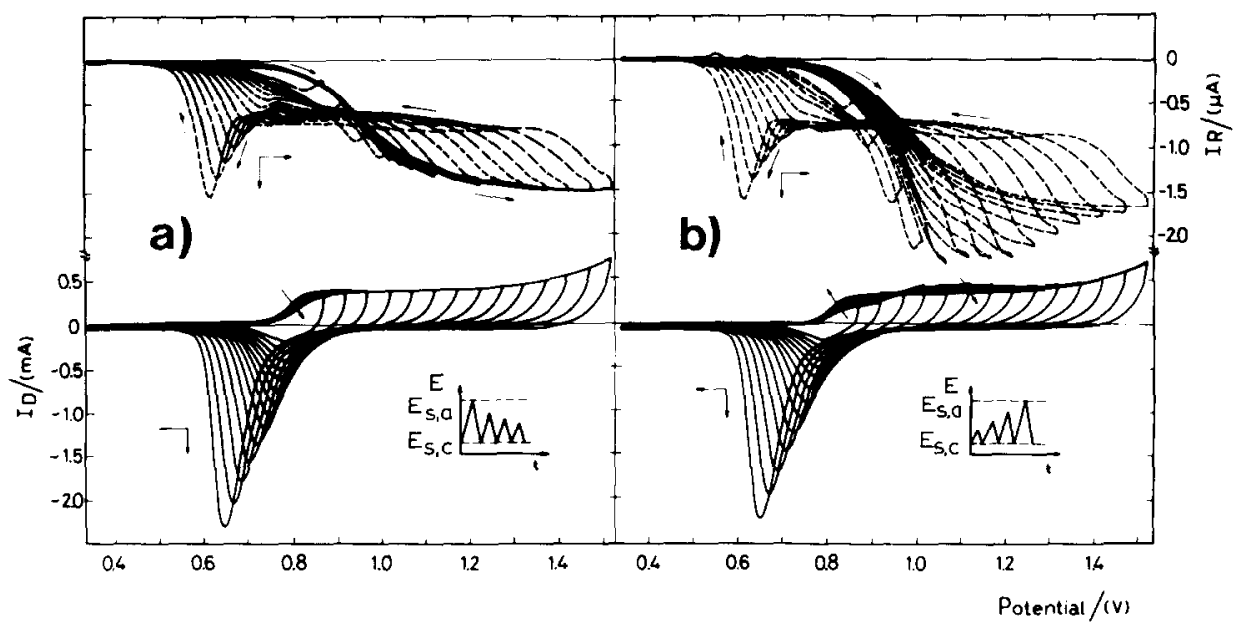

Fig. 2. $E_{\mathrm{D}} / I_{\mathrm{D}}$ and $E_{\mathrm{D}} / I_{\mathrm{R}}$ profiles at $0.2 \mathrm{~V} / \mathrm{s} . E_{\mathrm{R}}=0.38 \mathrm{~V} ; \omega-2000 \mathrm{rpm} ; \mathrm{Pd} / 1 M \mathrm{H}_{2} \mathrm{SO} \mathrm{O}_{4}$. $E_{\mathrm{s}, \mathrm{a}}$ stepwise changed downwards (a) and upwards (b). 
also show that the appearance of soluble $\mathrm{Pd}^{2+}$ at the ring electrode depends quite remarkably on the history of the electrode.

The ring current $\left(E_{\mathrm{R}}=0.38 \mathrm{~V}, v=0.2 \mathrm{~V} / \mathrm{s}\right)$ is practically independent 0 in the range $500 \mathrm{rpm} \leqslant \omega \leqslant 8000 \mathrm{rpm}$. This indicates that the entire amount of soluble product coming off the disc is collected at the ring (cathodic current contributions $\mathrm{I}_{\mathrm{a}}, \mathrm{II}_{\mathrm{a}}, \mathrm{III}_{\mathrm{a}}, \mathrm{IV}_{\mathrm{c}}, \mathrm{V}_{\mathrm{c}}, \mathrm{VI}_{\mathrm{c}}$ ) (Fig. 3). A remarkable current increase of the height of peak $\mathrm{VI}_{\mathrm{c}}$ is noticed when $E_{\mathrm{s}, \mathrm{a}}$ becomes more positive. In any case, the difference

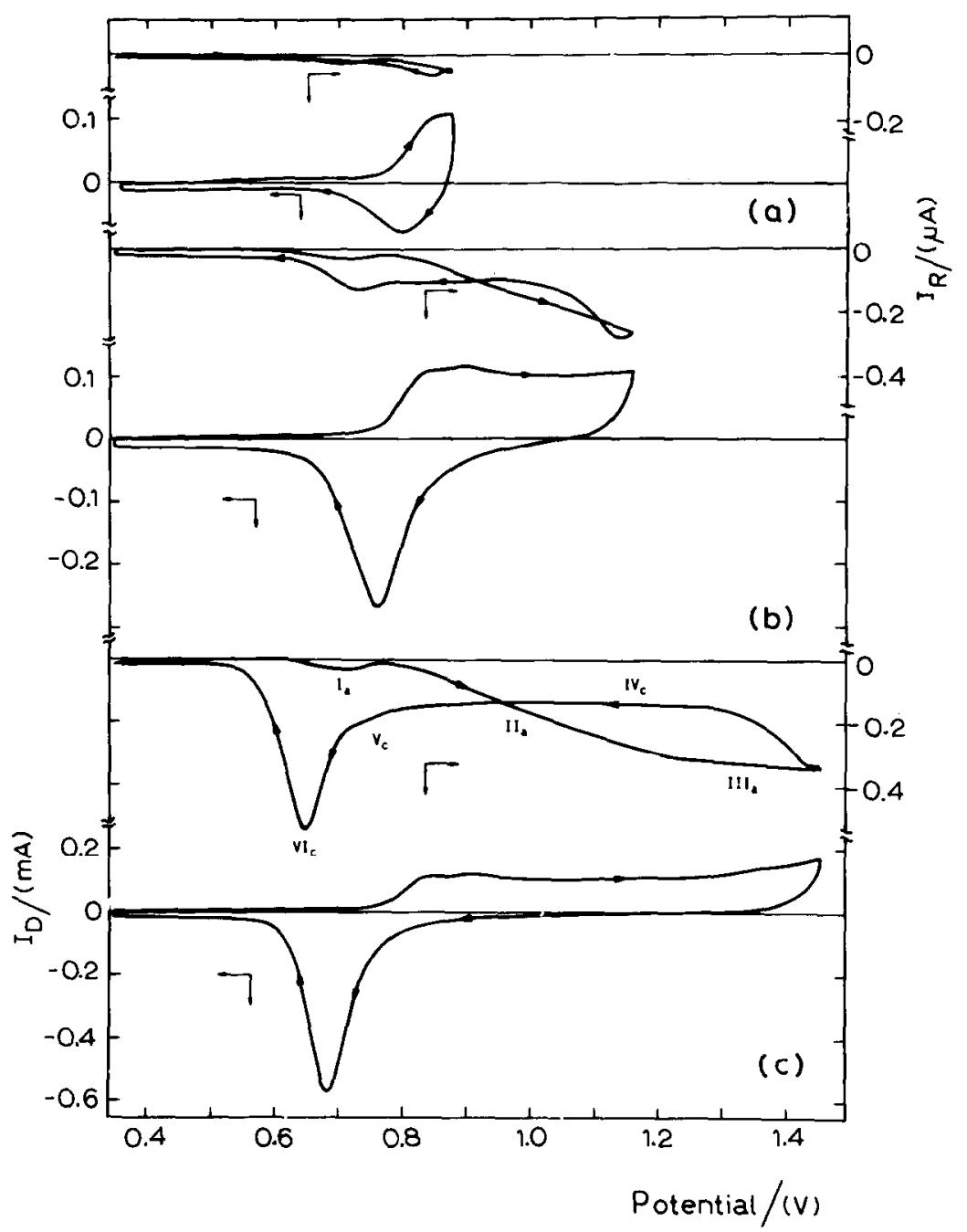

Fig. 3. Dependence of $E_{\mathrm{D}} / I_{\mathrm{D}}$ and $E_{\mathrm{D}} / I_{\mathrm{R}}$ profiles on $E_{\mathrm{s}, \mathrm{a}}$ at $n=0.2 \mathrm{~V} / \mathrm{s} E_{\mathrm{R}}=0.38 \mathrm{~V} ; \omega=2000 \mathrm{rpm}$; $\mathrm{Pd} / 1 \mathrm{M} \mathrm{H} \mathrm{H}_{2} \mathrm{SO}_{4}$. 
between the potential of peak $V I_{c}$ at the ring and the potential of the O-electroreduction peak at the disc, $E_{\mathrm{p}, \mathrm{i}}^{\mathrm{red}}-E_{\mathrm{p}, \mathrm{i}}$, is independent of $E_{\mathrm{s}, \mathrm{a}}$. It should be noted that the cathodic current ratio $I_{\mathrm{R}}^{+} / I_{\mathrm{R}}^{-}$depends on $E_{\mathrm{s}, \mathrm{a}}$. Thus, when $E_{\mathrm{s}, \mathrm{a}}<0.9 \mathrm{~V}$ (Fig. 3a), $I_{\mathrm{R}}^{+} / I_{\mathrm{R}}^{-}$is either greater or smaller than one depending on whether $E_{\mathrm{D}}$ is either more negative or more positive than $E_{\mathrm{i}}=0.725 \mathrm{~V}$. Otherwise, when $E_{\mathrm{s} . \mathrm{a}}>0.9 \mathrm{~V}($ Figs. $3 \mathrm{~b}$ and c), $I_{\mathrm{R}}^{+} / I_{\mathrm{R}}^{-}$is always smaller than one $E_{\mathrm{i}}<0.95 \mathrm{~V}$, while the reverse ratio is observed when $E_{\mathrm{i}}>0.95 \mathrm{~V}$.

When a potential step $\left(E_{\mathrm{r}}\right)$ is applied to the disc in the potential range preceding the O-electroadsorption process $\left(\mathrm{E}_{\tau}=0.68 \mathrm{~V}\right)$ during the time $\tau$, an inhibition of the O-electroadsorption process and an enhancement of the electrodissolution process at high positive potentials are observed (Fig. 4). In this case, the value of $E_{\mathrm{i}}$ related to the current loop at the ring remains practically constant. Likewise, as $\tau$ increases the current contribution $\mathrm{II}_{\mathrm{a}}$ decreases and that of $\mathrm{III}_{\mathrm{a}}$ increases. These effects can be assigned to the adsorption of $\mathrm{HSO}_{4}^{-}$ions which inhibits the electrodissolution process $\mathrm{II}_{\mathrm{a}}$ and promotes that process associated with the ring current contribution III $_{\mathrm{a}}$. Disulfate ion adsorption data on noble metal electrodes in acid electrolytes have already been reported in the literature $[20,21]$. The voltammogram of the

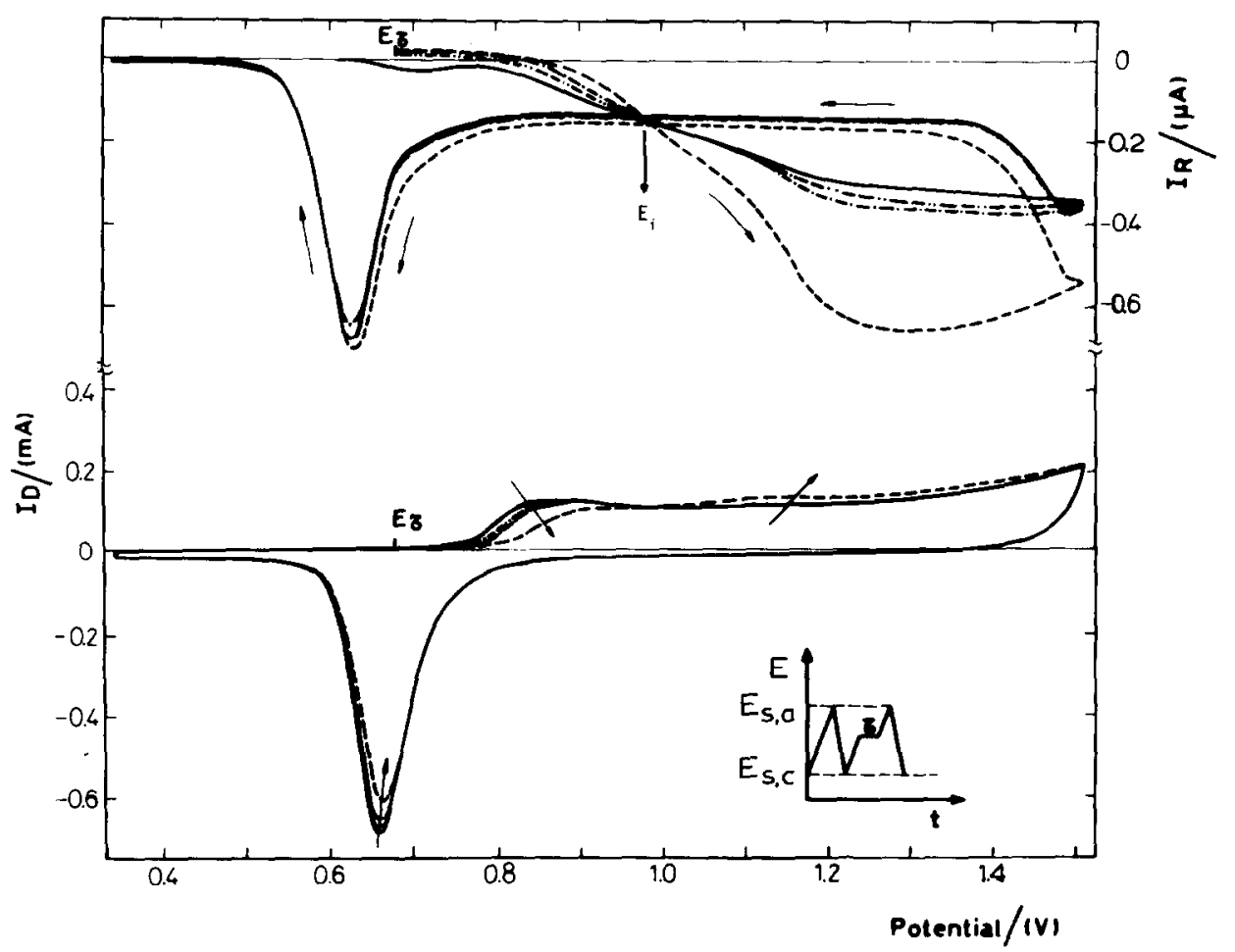

Fig. 4. $E_{\mathrm{D}} / I_{\mathrm{D}}$ and $E_{\mathrm{D}} / I_{\mathrm{R}}$ profiles after holding the potential at $E_{\tau}=0.68 \mathrm{~V}$ for different times, $\tau$ : $(-\cdots) 30 \mathrm{~s} ;(--) 1 \mathrm{~min} ;(-\ldots) .5 \mathrm{~min} . E_{\mathrm{R}}=0.38 \mathrm{~V} ; v=0.2 \mathrm{~V} / \mathrm{s} ; \omega=2000 \mathrm{rpm} ; \mathrm{Pd} / 1 \mathrm{M} \mathrm{H}_{2} \mathrm{SO}_{4}$. 
anodic layer produced at $E_{\mathrm{s}, \mathrm{a}}=1.52 \mathrm{~V}$ during $5 \mathrm{~min}$ is very similar to that already described for $E_{\tau}=0.68 \mathrm{~V}$, including the already known characteristic shifts of the electroreduction current peak [13] (Fig. 5). However, in contrast to RTPS experiments, the cathodic current at the ring immediately after stepping the potential at $E_{\tau}=E_{\mathrm{s}, \mathrm{a}}=1.52 \mathrm{~V}$ is smaller than that observed in the absence of the potential step, as reported earlier [6]. However, during the following RTPS, the $I_{R} / E_{D}$ profile approaches the shape of that observed for the corresponding stabilized RTPS voltammogram (Fig. 5). The current at the ring at $E_{\mathrm{R}}=0.38 \mathrm{~V}$ vs. the $E_{\mathrm{D}}$ profile resulting from the voltammetric run under the complex triangular potential per-

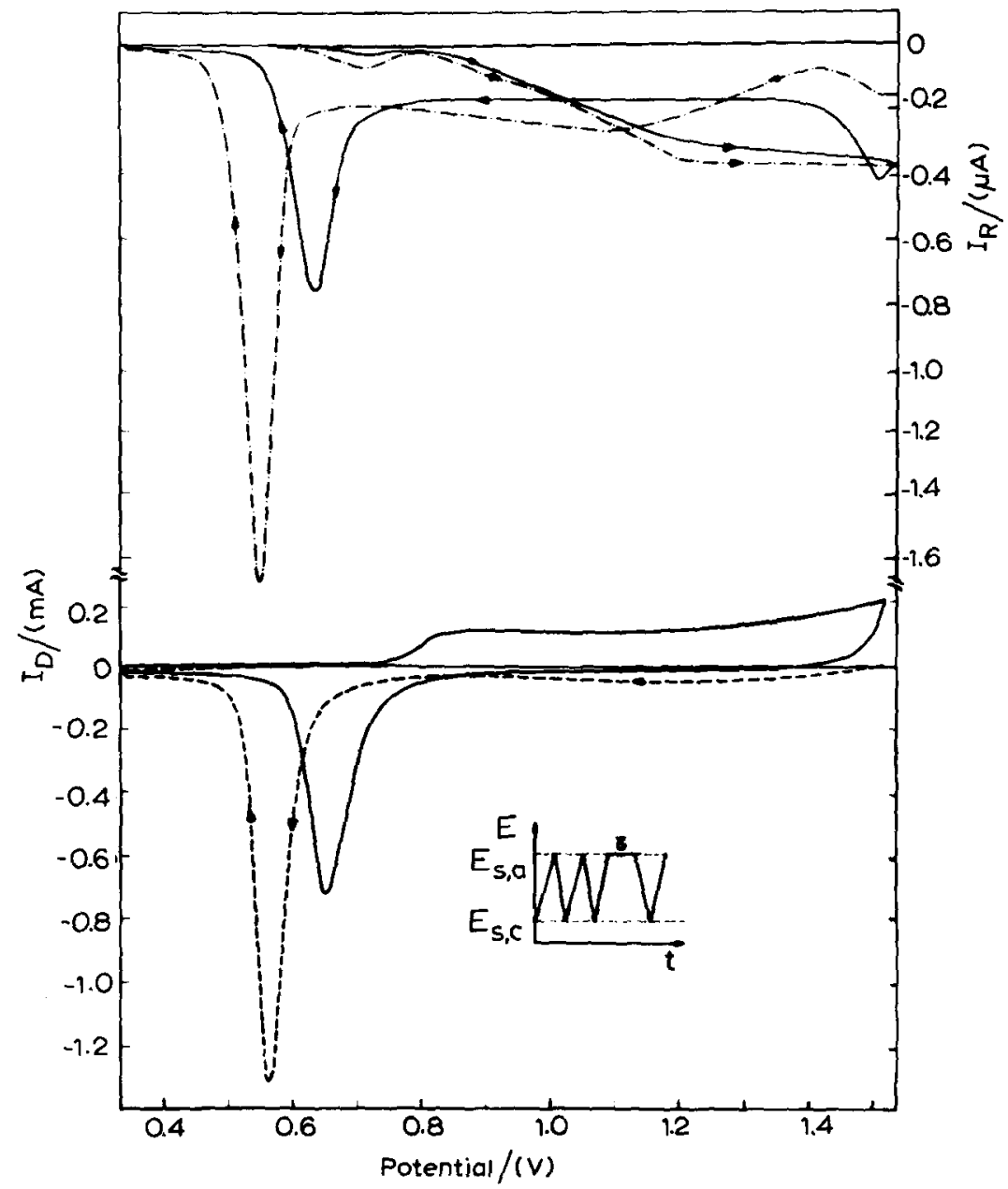

Fig. 5. $E_{\mathrm{D}} / I_{\mathrm{D}}$ and $E_{\mathrm{D}} / I_{\mathrm{R}}$ profiles resulting from TPS including a holding time $\tau=5 \mathrm{~min}$ at $E_{\tau}=1.52 \mathrm{~V}$. $E_{\mathrm{R}}=0.38 \mathrm{~V} ; v=0.2 \mathrm{~V} / \mathrm{s} ; \omega=2000 \mathrm{rpm} ; \mathrm{Pd} / 1 \mathrm{M} \mathrm{H}_{2} \mathrm{SO}_{4}$. 


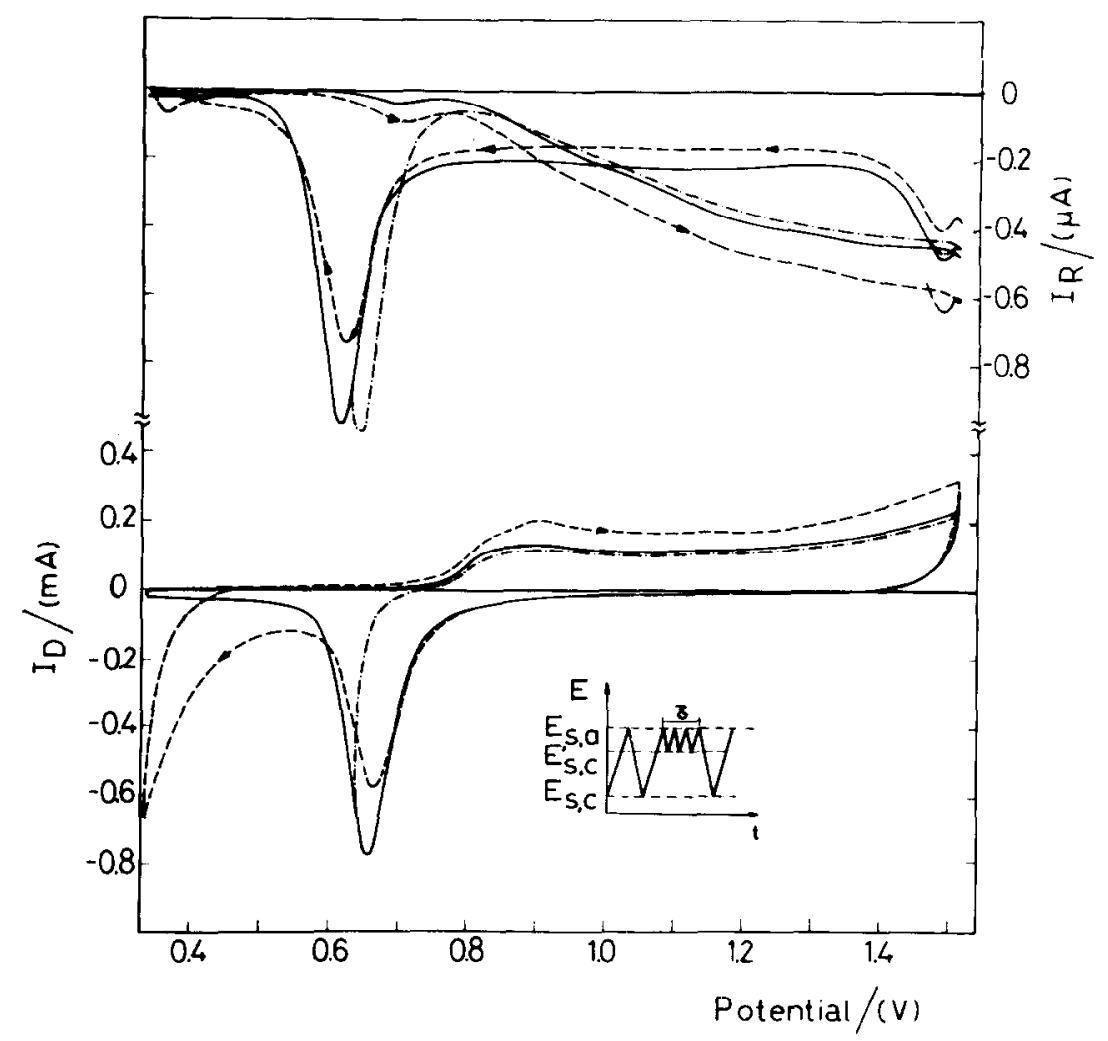

Fig. 6. $E_{\mathrm{D}} / I_{\mathrm{D}}$ and $E_{\mathrm{D}} / I_{\mathrm{R}}$ profiles obtained with a potentiodynamic ageing programme at $0.2 \mathrm{~V} / \mathrm{s}$. $E_{\mathrm{s}, \mathrm{c}}^{\prime}=0.63 \mathrm{~V}: \tau=10 \mathrm{~min} ; E_{\mathrm{R}}=0.38 \mathrm{~V} ; v=0.2 \mathrm{~V} / \mathrm{s} ; \omega=2000 \mathrm{rpm} ; \mathrm{Pd} / 1 M \mathrm{H}_{2} \mathrm{SO}_{4}$.

turbation depicted in Fig. 6 (potentiodynamic ageing experiments [22]) shows a new small cathodic current at the ring at ca. $E_{\mathrm{s}, \mathrm{c}}$, which is related to a soluble species formed during the electroreduction of the aged O-containing species. After potentiodynamic ageing, the electroreduced metal surface exhibits an apparent increase in real area as revealed by the charge increase associated with the electrochemical processes occurring at both the disc and the ring electrode.

\section{DISCUSSION}

It has already been established that the initial stage in the O-electroadsorption process takes place at the potential of electrodissolution of palladium according to the reaction:

$\mathrm{Pd}=\mathrm{Pd}^{2+}+2 e^{-}$

The thermodynamic threshold potential of reaction (1) is $E^{\circ}(\mathrm{SHE})=0.987$ [23]. 
This potential is similar to that of the overall reaction:

$\mathrm{Pd}+\mathrm{H}_{2} \mathrm{O}=\mathrm{PdO}+2 \mathrm{H}^{+}+2 e^{-}$

for which $E^{\circ}(\mathrm{SHE})=0.917 \mathrm{~V}$ [23].

Results obtained with a rotating disc electrode are free of palladium electrodeposition as the minor amount of soluble palladium formed during the anodization process is swept out of the reaction interface. In this case, practically no metal reforming [13] interferes with the corresponding voltammogram. These results also show clear evidence of the partial electrodissolution of palladium yielding soluble species during both the positive and the negative potential sweeps.

In the positive-going potential scan, the formation of soluble palladium ion occurs in the early stages of O-electroadsorption processes and continues at a constant rate up to $E_{\mathrm{s}, \mathrm{a}}$. The cathodic current at the ring electrode shows at least two current plateaux. One of them extends from ca. 0.35 to $0.75 \mathrm{~V}$ (in the disc) and the other one from 1.2 to $1.5 \mathrm{~V}$. Beyond $1.5 \mathrm{~V}$ the current in the ring increases abruptly. Analogously, the ring current during the negative-going potential sweep also becomes independent of the potential applied to the disc in the $1.50-0.85 \mathrm{~V}$ range. In this case, another dissolution process is associated with the O-electrodesorption current peak (Fig. 1) and the greatest dissolution appears when more than half of the O-electroadsorbed layer has disappeared. Therefore, it appears that the increase in yield of palladium(II)-soluble species should be mainly associated with two processes, namely the formation of $\mathrm{PdOH}$ as an intermediate either in the electrodissolution of the base metal or in the anodic oxygen containing layer growth, and the presence of $\mathrm{Pd}_{x} \mathrm{O}_{y}$ species where $1 \leqslant y / x \leqslant 2$.

When only the early stages of the anodic film growth are covered (low $E_{\mathrm{s}, \mathrm{a}}$ ), the current at the ring in the negative-going potential scan is greater than that recorded in the reversc scan. Howcver, when $E_{\mathrm{s}, \mathrm{a}}$ excecds $0.95 \mathrm{~V}$, then the $E_{\mathrm{D}} / I_{\mathrm{R}}$ profile exhibits a crossing point at ca. 1.1-1.2 V, a potential range which is close to the thermodynamic threshold potential of $\mathrm{PdO}_{2}$ electroformation [23]. Hence, the appearance of soluble palladium(II) in solution should be related, in part, to the formation of $\mathrm{Pd}_{x} \mathrm{O}_{y}$ species. Apparently, the maximum yield of soluble palladium(II) is associated with the electroformation of $\mathrm{Pd}(\mathrm{OH})$ and $\mathrm{PdO}_{2}$ at the electrode surface. The appearance of soluble palladium(II) must also be influenced by the local changes in $\mathrm{pH}$ which are produced during both the anodization (acidification) and cathodization (alkalinization) processes [24].

A clear picture of the formation of soluble palladium species can be obtained by plotting the ring current to disc current ratio for both the anodic and the cathodic reactions as a function of the applied potential (Fig. 7). In the absence of promoted ageing, the potential difference between the corresponding minimum electrodissolution effeciencies is the same as that of the current peaks associated with the initial O-electroadsorption and O-electrodesorption processes, respectively. Ageing effects shift the potential of the minimum electrodissolution efficiency towards more negative potentials and modify the $I_{\mathrm{R}} / I_{\mathrm{D}}$ vs. $E_{\mathrm{D}}$ plot, particularly above $0.8 \mathrm{~V}$.

The formation of soluble palladium(II) in the low potential range can be 


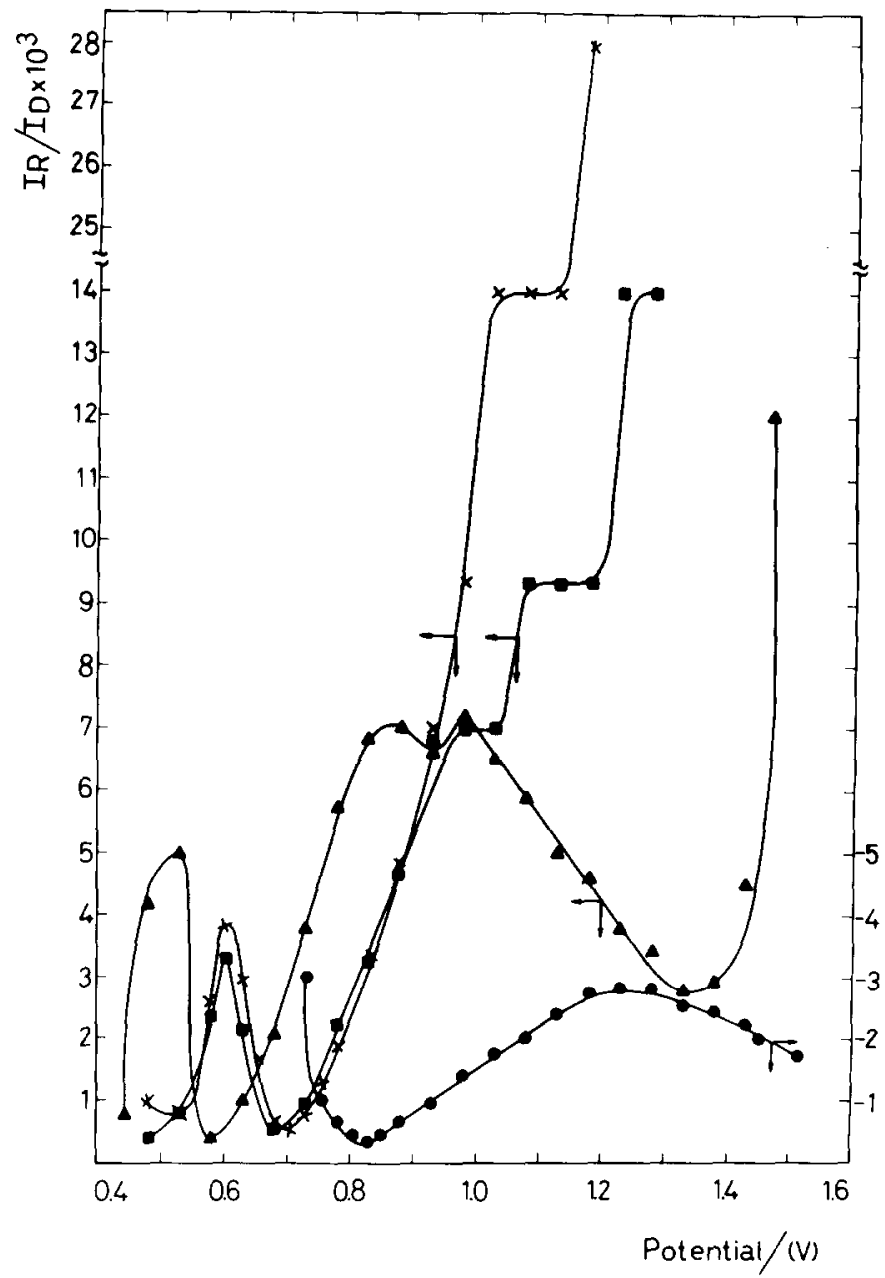

Fig. 7. Plots of $I_{\mathrm{R}} / I_{\mathrm{D}}$ vs. $E_{\mathrm{D}} \cdot E_{\mathrm{R}}=0.38 \mathrm{~V} ; v=0.2 \mathrm{~V} / \mathrm{s} ; \omega=2000 \mathrm{rpm} ; \mathrm{Pd} / 1 M_{2} \mathrm{H}_{2} \mathrm{SO}_{4}$, (-) positive potential scan; (x) negative potential scan; (A) negative potential scan after holding the disc at $E_{\tau}=1.52 \mathrm{~V}$ for $5 \mathrm{~min}$ (Fig. 5); ( $(\boldsymbol{\theta})$ negative potential scan after applying a potential ageing programme with $E_{\mathrm{s}, \mathrm{c}}^{\prime}=0.63 \mathrm{~V}$ during $10 \mathrm{~min}$ (Fig. 6).

explained on the basis of a competitive process for the initial PdOH intermediate obtained by the reversible underpotential oxidation of water, according to:

$\mathrm{Pd}+\mathrm{H}_{2} \mathrm{O} \rightleftarrows \mathrm{Pd}(\mathrm{OH})+\mathrm{H}^{+}+e^{-}$

Reaction (1) is the common initial step rclated to both the base metal electrodissolution and the O-electroadsorption in acid. In the former case, the electrodissolution process continues as follows:

$\mathrm{Pd}(\mathrm{OH})=\mathrm{Pd}(\mathrm{OH})^{+}+e^{-}$ 
$\mathrm{Pd}(\mathrm{OH})^{+} \rightleftarrows \mathrm{Pd}^{2+}$ (aq.) $+\mathrm{OH}^{-}$

yielding soluble palladium(II). On the other hand, the alternative reaction proceeds through the following stages:

$\mathrm{Pd}(\mathrm{OH})=\mathrm{Pd}(\mathrm{O})+\mathrm{H}^{+}+e^{-}$

$\operatorname{Pd}(\mathrm{O}) \rightarrow$ Oxygen-containing layer

which correspond to the anodic oxygen containing film formation. Reactions (4b) and (6) denote complex overall reactions where ageing, disproportionation and peroxide formation processes discussed in a previous publication [13] are not considered here. This reaction pathway (3-5) is, in principle, formally similar to that proposed for the stationary and non-stationary electrodissolution of many metals in aqueous acid electrolytes [25]. The non-stationary electrodissolution of palladium occurs, however, in three potential regions related to the electroformation of oxygen-containing species [7,13], as expressed by the following overall reactions:

$\mathrm{Pd}+\mathrm{H}_{2} \mathrm{O}=\mathrm{Pd}(\mathrm{OH})+\mathrm{H}^{+}+e^{-}$

$\mathrm{Pd}+\mathrm{H}_{2} \mathrm{O}=\mathrm{PdO}+2 \mathrm{H}^{+}+2 e^{-}$

$\mathrm{Pd}+2 \mathrm{H}_{2} \mathrm{O}=\mathrm{PdO}_{2}+4 \mathrm{H}^{+}+4 e^{-}$

According to results obtained for the corrosion and passivation of other metals in acid electrolytes [25], the rates of the competing electrodissolution and electrooxidation processes are probably determined by steps (4a) and (4b), respectively. In this case, the corresponding rate equations can be written in terms of the apparent current densities ( $i_{\mathrm{diss}}$ and $i_{\mathrm{ox}}$, respectively) as follows:

$i_{\text {diss }}=k_{\text {diss }} \theta_{\mathrm{PdOH}} \exp \left\{\alpha_{1} F E_{\mathrm{D}} / R T+\Delta G_{\text {diss }}^{*} / R T\right\}$

and

$i_{\mathrm{ox}}=k_{\mathrm{ox}} \theta_{\mathrm{PdOH}} \exp \left\{\alpha_{2} F E_{\mathrm{D}} / R T+\Delta G_{\mathrm{ox}}^{*} / R T\right\}$

where the $k$ 's correspond to formal rate constants in electrical units, $\theta_{\mathrm{PdOH}}$ is the degree of surface coverage by $\mathrm{OH}$ species at the applied potential $E_{\mathrm{D}}$, the $\alpha$ 's denote the transfer coefficients for both reactions in the anodic direction and the $\Delta G^{*}$ 's are electrically independent Gibbs energy contributions of the corresponding anodic processes. Under potentiodynamic conditions, $E_{\mathrm{D}}=E_{\mathrm{i}}+v t, \theta_{\mathrm{PdOH}}$ goes through a maximum $[26,27]$ and, correspondingly, the maximum $i_{\text {diss }}$ value should be attained. However, at any potential value $\left(0.4 \mathrm{~V} \leqslant E_{\mathrm{D}} \leqslant 1.5 \mathrm{~V}\right)$ the experimental $I_{\mathrm{R}} / I_{\mathrm{D}}$ $\left(i_{\mathrm{diss}} / i_{\mathrm{ox}}\right)$ ratio is always much lower than 0.25 , the maximum value which would result from the design of the ring-disc electrode. This confirms that only a relatively small fraction of the whole charge involved in each potential scan appears in the electrodissolution process [6].

At a constant potential, the value of the $i_{\text {diss }} / i_{\text {ox }}$ ratio can be tentatively assigned to the difference in the $\Delta G^{*}$ terms, providing that $k_{\text {diss }} \simeq k_{\mathrm{ox}}$ and $\alpha_{1} \simeq \alpha_{2}$. Thus the estimated difference is $\Delta G_{\text {diss }}^{*}-\Delta G_{\text {ox }}^{*} \simeq 25 \mathrm{~kJ} / \mathrm{mol}$. This Gibbs energy difference should be related to the degree of activation of the electrode surface for the 
electrodissolution process, which should depend on surface reconstruction, surface reforming and metal surface-anion-solvent interactions. The difference in the $\Delta G^{*}$ terms is also probably associated with the proper nature of reactions (4a) and (4b), as for the latter the electron transfer implies a simultaneous proton transfer into solution.

It is clear that by holding the potential in the double-layer region where specific adsorption of $\mathrm{HSO}_{4}^{-}$ion takes place the initiation of the O-electroadsorption is delayed and at high positive potentials the metal electrodissolution is enhanced (Fig. 4). The former effect is the same as that already reported for other noble metals in acid electrolytes $[20,21]$. The enhancement of the electrodissolution process induced by anion adsorption can be explained by a local electrical field effect due to the surface dipoles produced when the applied potential is either positive or negative with respect to the pzc of the electrochemical interface $\left(E_{\mathrm{pzc}}^{\mathrm{Pd} / \mathrm{H}_{2} \mathrm{SO}_{4}} \approx 0.2 \mathrm{~V}\right.$ ) [28]. Hence, when the palladium electrode is positively charged, the reaction related to local metal-anion interaction can be schematically represented as follows:

$$
\begin{array}{lll}
(+) \mathrm{Pd}(\mathrm{OH})_{\mathrm{ad}} & \cdots \mathrm{HSO}_{4}^{-} \rightleftarrows\left|\mathrm{Pd}(\mathrm{OH})^{+}\right|\left|\mathrm{HSO}_{4}^{-}\right| & \\
(+) \mathrm{Pd}(\mathrm{O})_{\mathrm{ad}} & \cdots \mathrm{HSO}_{4}^{-} \rightleftarrows\left|\mathrm{Pd}(\mathrm{O})^{+}\right|\left|\mathrm{HSO}_{4}^{-}\right| & \mathrm{PdSO}_{4}(\mathrm{aq} .)
\end{array}
$$

where equilibrium between different structures are considered, one of them heing a precursor in the formation of the highly soluble palladium sulphate [29].

On the other hand, the chemical dissolution of the $\operatorname{Pd}_{x} \mathrm{O}_{y}$ layer should depend on whether its composition approaches the $\mathrm{PdO}$ or $\mathrm{PdO}_{2}$ stoichiometry. In any case, because of the low stability of palladium(IV) species in aqueous solutions [2], only palladium(II) species are formed in solution.

The chemical dissolution of the $\mathrm{Pd}_{x} \mathrm{O}_{y}$ electroformed layer can be interpreted as a two-stage process, also involving $\mathrm{Pd}(\mathrm{OH})^{+}$as the reaction intermediate. Thus for the simplest palladium-oxygen stoichiometry:

$\mathrm{PdO}+\mathrm{H}^{+} \rightleftarrows \mathrm{Pd}(\mathrm{OH})^{+}$
$\mathrm{Pd}(\mathrm{OH})^{+} \rightleftarrows \mathrm{Pd}^{2+}+\mathrm{OH}^{-}$

and for $\mathrm{PdO}_{2}$ :

$$
\begin{aligned}
& \mathrm{PdO}_{2}+\mathrm{H}^{+} \rightleftarrows \mathrm{Pd}(\mathrm{OH})^{+}+\frac{1}{2} \mathrm{O}_{2} \\
& \mathrm{Pd}(\mathrm{OH})^{+} \rightleftarrows \mathrm{Pd}^{2+}+\mathrm{OH}^{-}
\end{aligned}
$$

Step (14a) may be responsible, in part, for the production of vestiges of molecular oxygen. It is possible that traces of oxygen also result from the chemical decomposition of electrochemically formed, relatively unstable peroxide-type structures. This type of reaction occurs in the case of gold electrodes in acid electrolytes already at potentials slightly below that usually assigned to the completion of the O-electroadsorbed monolayer [30].

The same type of analysis can be extended to the O-electrodesorption process. The overall reaction is formally represented by the equation:

$\mathrm{PdO}+\mathrm{H}_{2} \mathrm{O}+2 e^{-} \rightleftarrows \mathrm{Pd}+2 \mathrm{OH}^{-}$ 
which also implies the participation of $\mathrm{Pd}(\mathrm{OH})$ species according to:

$$
\begin{array}{ll}
\mathrm{Pd}(\mathrm{O})+\mathrm{H}_{2} \mathrm{O}+e^{-} & \rightleftarrows \mathrm{Pd}(\mathrm{OH})+\mathrm{OH}^{-} \\
\mathrm{Pd}(\mathrm{OH})+e^{-} & \rightleftarrows \mathrm{Pd}+\mathrm{OH}^{-}
\end{array}
$$

and eventually the occurrence of reaction (13b) yielding soluble palladium(II). As the maximal $\mathrm{Pd}(\mathrm{OH})$ surface concentration is attained close to the electrodesorption peak potential, the formation of $\mathrm{Pd}(\mathrm{OH})^{+}$and soluble $\mathrm{Pd}^{2+}$ should then be considerably enhanced, as was actually observed.

\section{ACKNOWLEDGEMENTS}

INIFTA is sponsored by the Consejo Nacional de Investigaciones Cientificas y Técnicas, the Universidad Nacional de La Plata, and the Comisión de Investigationes Cientificas (Provincia de Buenos Aires).

\section{REFERENCES}

1 K.J. Vetter and N. Berndt, Z. Elektrochem., 62 (1958) 378.

2 J.F. Llopis and F. Colom in A.J. Bard (Ed.), Encyclopedia of Electrochemistry of the Elements, Vol. 6, Marcel Dekker, New York, 1975, p. 253.

3 A.R. Blake, J.G. Sunderland and A.T. Kuhn, J. Chem. Soc. A, (1969) 3015.

4 A. Goodridge and C.J.H. King, Trans. Faraday Soc., 66 (1970) 2889.

5 D.A.J. Rand and R. Woods, J. Electroanal. Chem., 35 (1972) 209.

6 S.H. Cadle, J. Electrochem. Soc., 121 (1974) 645.

7 K. Gossner and E. Mizera, J. Electroanal. Chem., 125 (1981) 347.

8 T. Chierchie, C. Mayer and W. Lorenz, J. Electroanal. Chem., 135 (1982) 211.

9 J.F. Llopis, M.M. Gamboa and L. Victori, Electrochim. Acta, 17 (1972) 2225.

10 J.N. Crosby, J.A. Harrison and T.A. Whitfield, Electrochim. Acta, 26 (1981) 1647.

11 J. N. Crosby, J.A. Harrison and T.A. Whitfield, Electrochim. Acta, 27 (1982) 897.

12 J.A. Harrison and T.A. Whitfield, Electrochim. Acta, 28 (1983) 1229.

13 A.E. Bolzán, M.E. Martins and A.J. Arvía, J. Electroanal. Chem., 157 (1983) 335.

14 S.H. Cadle, Anal. Chem., 46 (1974) 587.

15 R. Woods, in A.J. Bard (Ed.), Electroanalytical Chemistry, Vol 9, Marcel Dekker, New York, 1977, Ch. 1.

16 G. Bélanger and A.K. Vijh in A.K. Vijh (Ed.), Oxides and Oxide Films, Vol. 5, Marcel Dekker, New York, 1977, Ch. 1.

17 W.J. Albery and M.L. Hitchman, Ring-Disc electrodes, Clarendon Press, Oxford, 1971.

18 B.E. Conway, H. Angerstein-Kozlowska and W.B.A. Sharp, Anal. Chem., 45 (1973) 1331.

19 D.T. Napp, D.C. Johnson and S. Bruckenstein, Anal. Chem., 39 (1967) 481.

20 R.O. Lezna, N.R. de Tacconi and A.J. Arvia, J. Electrochem. Soc., 126 (1979) 2140.

21 M.I. Florit, M.E. Martins and A.J. Arvia, J. Electroanal. Chem., 151 (1983) 209.

22 A.J. Arvia, Isr. J. Chem., 18 (1979) 89.

23 M. Pourbaix, Atlas of Electrochemical Equilibria in Aqueous Solutions, Pergamon Press, Oxford, 1966.

24 A.T. Kuhn and C.Y. Chan, J. Appl. Electrochem., 13 (1983) 189.

25 A.J. Arvia, Proceedings of the 8th International Congress on Metallic Corrosion, Vol. 3, Dechema, Frankfurt am Main, 1981, p. 2065.

26 S. Srinivasan and E. Gileadi, Electrochim. Acta, 11 (1966) 321.

27 N.R. de Tacconi, J.O. Zerbino and A.J. Arvia, J. Electroanal. Chem., 79 (1977) 287.

28 L. Campanella, J. Electroanal. Chem., 28 (1970) 228.

29 R.C. Weast (Ed.), Ilandbook of Chemistry and Physics, CRC Press, Cleveland, 57th ad., 1977, p. B138.

30 M.I. Florit, M.E. Martins and A.J. Arvia, J. Electroanal. Chem., 126 (1981) 255. 